\title{
04 MOLECULAR AND MICROBIOLOGICAL DIAGNOSIS
}

04.001 - DETECTION OF PARACOCCIDIOIDES BRASILIENSIS GP43 GENE IN SPUTA BY LOOP-MEDIATED ISOTHERMAL AMPLIFICATION METHOD (LAMP)

Tatibana, B. T. ${ }^{1}$; Sano, A²; Uno, J. ${ }^{3}$; Kamei, K.. ${ }^{4}$ Igarashi, T. ${ }^{5}$ Mikami, Y.6 ${ }^{6}$ Miyaji, M. ${ }^{7}$; Nishimura, K. ${ }^{8}$; Itano, E. N. ${ }^{9}$

${ }^{1,9}$ State University of Londrina - Department of Pathology Science, Londrina, PR, Brazil; ${ }^{2,3,4,5,6,7,8}{ }^{2}$ Chiba University - Research Center for Pathogenic Fungi and Microbial Toxicoses, Chiba, Japan.

Introduction and Objectives: Paracoccidioidomycosis (PCM), caused by the thermally dimorphic fungus Paracoccidioides brasiliensis $(\mathrm{Pb})$, is the most prevalent systemic mycoses in Latin America. The diagnostic of PCM is sometimes difficult in outside endemic areas. The LAMP has the advantages of rapid reaction, simple operation, and easy detection that required few hours from fungal DNA extraction to identification. In the present study, we have evaluated a LAMP method to unambiguously PCM diagnosis detecting gp43 gene of $P$. brasiliensis in clinical sputa specimens obtained from a group of Brazilian PCM patients. Methods and Results: A total of 23 sputa samples obtained from 21 patients with chronic PCM (male, aged 28 to 72 years) with a diagnostic established by x-ray, clinical data, and isolation by culture and/or serological tests were used in this study. By using one set of primers F3 for LAMP, B3, FIP, and BIP designed from the partial sequence of gp43 (GenBank accession number U26160), the LAMP assay rapidly amplified the target gene in less than h. We obtained positive results in 11 out of 23 sputa samples of PCM patients $(47.8 \%)$ Conclusion: Detection of gp43 gene specie specific in sputum can be very useful because it is a nonculture method, can be performed rapidly and do not require invasive sampling procedures. The present study was the first one to apply LAMP method to investigate $P$ brasiliensis gp 43 gene in sputum specimens. Although further study is necessary for its widespread use, we believe that LAMP method might be applicable to diagnosis of PCM.

\subsection{2 - M51 SEQUENCE: A NEW MOLECULAR MARKER FOR} PARACOCCIDIODOMYCOSIS DIAGNOSIS

Bernardes, V. V. ${ }^{1}$; Bocca, A. L. ${ }^{2}$; Silva, S. S. ${ }^{3}$; Silva Pereira, I. ${ }^{4}$; Felipe, M. S. S. ${ }^{5}$

${ }^{1} U n B$ - Cell Biology; ${ }^{2}$ University of Brasilia - Cell Biology Department; ${ }^{3}$ UnB - BIOLOGIA MOLECULAR ; ${ }^{4} U n B$ - Biologia Celular; ${ }^{5}$ UnB - Departament of Cell Biology

Introduction and Objectives: Paracoccidioides brasiliensis $(\mathrm{Pb})$ is a dimorphic fungus that causes the paracoccidioidomycosis (PCM), a systemic granulomatous mycosis considered the most important endemic mycosis of Latin America. The definitive diagnosis of PCM includes the direct microscopy observation of the characteristic multiple budding cells or isolation of the fungus from clinical samples. Culturing clinical samples can be timeconsuming and lead to false positive results. If the fungus remains undetected, the diagnosis is confirmed by several serological tests. Among the molecular methods, the polymerase chain reaction (PCR) has been the most used approach to identify several other fungi included $\mathrm{Pb}$. The objective of this work was to standardize a PCR using a new sequence, the M51, for PCM diagnosis. Methods and Results: The M51 is a mycelium up-regulated gene, a possible non-coding RNA, and was confirmed as differentially expressed in the transcriptome analysis in "Functional and Differential Genome Project of P. brasiliensis" (FEMS Immunol. Med. Microb. 2005, in press). For the standardization a PCR was performed with the primers $\mathrm{U} 19 \mathrm{~F}$ and R1, complementary primers for the DNA sequence M51. To verify if these primers presented crossed reaction and/or intra-specific differences, assays were carried out with the total DNA of diverse fungi and with the total DNA of 19 isolated of $\mathrm{Pb}$. The results confirmed the specificity of the primers. To tackle sensitivity, decreasing concentrations of the genomic DNA from Pb01 were used as templates in PCRs. The lesser-amplified concentration was $0,15625 \mathrm{ng} / \mu \mathrm{L}$ of the sample of genomic DNA from $\mathrm{Pb}$. To evaluated specificity of primers using human biological fluid, we added yeast from $\mathrm{Pb} 01\left(10^{6}, 10^{5}, 10^{4}, 10^{3}, 10^{2}, 10^{1} \mathrm{~Pb}\right.$ cells $/ \mathrm{mL}$ ) in samples of blood and washed broncoalveolar (BAL) from healthful person. The results demonstrated amplification from $\mathrm{Pb}$ DNA until $10^{1}$ cells $/ \mathrm{mL}$ for blood samples and $10^{2}$ cells / $\mathrm{mL}$ for BAL. Conclusion: Despite the other sequences used for PCM diagnosis, as gp43, the results demonstrated that a PCR using DNA M51 from Pb has a high sensitivity and specificity and can be used in molecular diagnosis in clinical samples. Financial support: CNPq, MCT and FAP-DF.

\subsection{3 - IDENTIFICATION OF GENETIC GROUPS OF PARACOCCIDIOIDES} BRASILIENSIS (PB) IN PARAFFIN-EMBEDDED TISSUE

Ricci, G. ${ }^{1}$; Zelck, U. ${ }^{2}$; Tito Mota, F. ${ }^{3}$; Franco, M..$^{4}$; Bialek, R. ${ }^{5}$

${ }^{1,4}$ Unifesp - Patologia; ${ }^{2}$ Tübingen University - Inst.Trop.Medicine; ${ }^{3}$ Lab.Patologia - Mogi Iguaçu; ${ }^{5}$ Tübingen University - Inst.Med.Tropical

Introduction\&Objetive: Since paracoccidioidomycosis (PCM) is often diagnosed by histopathology, the aim of this study was to identify and genotype $P b$ from paraffin-embedded tissue samples. Material \& Methods: 10 paraffin-embedded biopsies were used to DNA extraction (Qiagen Mini Kit)(1). The 231-nucleotide PCR products were sequenced using the Big Bye terminator cycle sequencing kit and ABI sequencer. Results: Specific nested PCRs were run targeting genes encoding the gp 43 and the $100 \mathrm{kDa}$-like protein of Histoplasma capsulatum $(H c)(1,2)$. We created two semi-nested PCR assays using outer primer Para I and inner primer Para IV, as well as the outer primer Para II and the nested primer Para III (2). In one sample, no DNA was amplified by the gp 43 PCR whereas the $100 \mathrm{kDa}-\mathrm{PCR}$ was positive, indicating presence of $H c$ specific DNA. In the remaining 9 samples, only $P b$ specific DNA was amplified. From 5 samples 2 expected PCR products of $303 \mathrm{bp}$ and 248 bp were amplified and sequenced from both ends. The sequences from each sample were aligned, combined to one sequence of 355 nucleotides and compared with nucleotide positions 520 to 874 of the gp43 gene consensus sequence from GenBank (accession number AY005428). Three gp43 sequences were identical to the consensus sequence without mutation at either informative or noninformative sites identifying them as a genotype of clade 3 (3). Two other sequences showed mutations: G 578 A, A 617 G, A 628 G, A 751 G, G 763 C, G 799 T, T 830 $\mathrm{C}, \mathrm{G} 856 \mathrm{~A}$, and T $872 \mathrm{~A}$, but no mutation at positions $589,821,852,874$ and the noninformative sites. They are identical to the formerly described polymorphic strains $\mathrm{Pb} 2$ and $\mathrm{Pb} 3$, defined as genotype $\mathrm{A}$. Thus, the infecting $\mathrm{Pb}$ isolates in the tissue samples belong to the genotype A which is phylogenetically distant from the others (4). Conclusion: Our preliminary results show that polymorphism within the gp43 gene is detectable in infected tissue which is not attributable to passages in cultures and animals. Our modified diagnostic nested PCR enables identification and genotyping of $P b$ directly from paraffin-embedded lesional biopsies. References: (1)J. Clin. Microbiol. 40:1644-47, 2002. (2) J. Clin. Microbiol. 38:2940-2942, 2000 (3) J. Clin. Microbiol. 38:3960-3966, 2000 (4) Microbes Infect. 7:55 65, 2005 Acknowledgment: Ricci G received grants from CAPES and DAAD (Germany).

\subsection{4 - HETEROLOGOUS EXPRESSION, PURIFICATION AND IMMUNOLOGICAL REACTIVITY OF THE RECOMBINANT GLYCERALDEHYDE-3- PHOSPHATE DEHYDROGENASE FROM PARACOCCIDIOIDES BRASILIENSIS}

Barbosa, M. S. ${ }^{1}$; Santos, R. S. ${ }^{2}$; Zancope-Oliveira, R. M. ${ }^{3}$; Felipe, M. S. S. ${ }^{4}$; Soares, C. M. A. ${ }^{5}$ ${ }_{1,2,5}$ UFG - Department of Biochemistry and Molecular Biology ; ${ }^{3}$ FIOCRUZ - Institute of Clinica Research Evandro Chagas ; ${ }^{4}$ UnB - Departament of Cell Biology

Introduction and Objectives Paracoccidioides brasiliensis is the ethiological agent of paracoccidioidomycosis (PCM) a major medical problem in Latin America. The fungus mycelia propagules when inhaled differentiate to the yeast phase establishing the infection in the human lungs. The disease establishment depends, among several aspects, on the ability of the fungus to modulate the host immune system. Glyceraldehyde-3-phosphate dehydrogenase (GAPDH) has been characterized by our laboratory as a immunogenic protein of $P$. brasiliensis. Methods and Results In a previous work we have cloned the complete cDNA encoding the $36-\mathrm{kDa}$ GAPDH of $P$. brasiliensis. In this work, the cDNA encoding the $P$. brasiliensis GAPDH was subcloned into the expression vector TOPO pET100 to obtain the recombinant fusion protein. The protein was overexpressed in an Escherichia coli host to produce high levels of recombinant protein that was purified by affinity chromatography. The recombinant protein was evaluated regarding to its immunological reactivity with sera of PCM patients. A total of 70 human serum samples were tested for reactivity by Western blot analysis with the purified recombinant GAPDH (rGAPDH) protein. Immunoblots indicated that the rGAPDH was able to react with antibodies present in all sera of PCM patients, but in not in sera of control individuals. Conclusion The rGAPDH can be a valuable addition to the still small arsenal of $P$. brasiliensis immunoreactive proteins, which could be tested for incorporation into assays for serodiagnosis of the disease Financial support: CAPES and MCT/CNPq. 
04.005 - ASSOCIATION OF CULTURE, HISTOPATHOLOGY, SEROLOGY AND MOLECULAR TOOLS FOR THE DIAGNOSIS OF DERMATOLOGICAL LESIONS OF PARACOCCIDIOIDOMYCOSIS (PCM). PRELIMINARY RESULTS Siqueira, K. Z. ${ }^{1}$; Bosco, S. M. G. ${ }^{2}$; Parise-Fortes, M. R. ${ }^{3}$; Marques, M. E. ${ }^{4}$; Peraçoli, M. T. S. Bagagli, E. ${ }^{6}$; Marques, S. A. ${ }^{7}$

1,2,5,6IB - Unesp - Botucatu - Microbiologia e Imunologia; ${ }^{3,7}$ Faculdade de Medicina de Botucatu Dermatologia e Radioterapia; ${ }^{4}$ Faculdade de Medicina de Botucatu - Patologia

Introduction and Objectives: Paracoccidioides brasiliensis is the etiological agent of PCM, one of the most important and prevalent systemic mycoses in Latin America, occurring as an endemic disease mainly in Brazil, Colombia, Venezuela and Argentina. Clinically, the disease is classified as acute or juvenile and as a chronic or adult form. Cutaneous and/or mucocutaneous lesions are a very common clinical expression of chronic disease that in some cases complicate the welfare of the patient. The pathogen detection is very important in optimising therapy and differentiating it from other parasitic dermatological lesions. The aim of this study was to evaluate the sensitivity of four methods in detection of $P$. brasiliensis in patients with dermatological lesions. Methods and Results: 12 patients (10 males and 2 females), ranging from 43 to 66 years old, proceeding from Botucatu endemic region during February/04 to May/05, were examined for cutaneous and mucocutaneous lesions of PCM in the Dermatology service of Hospital das Clínicas, FMB/UNESP. A $5 \mathrm{~mm}$ punch biopsy was colleted for culture, histopathology and Nested-PCR using sets of primers derived from rDNA. Serology was also carried out using immunodiffusion (RID) and ELISA assays. The lesions were most frequently observed in the cutaneous/ mucocutaneous areas of the face. Fungal recovery in culture was positive in six biopsy samples, while histopathology was able to detect the pathogen in all of them. With regard to serology, ten patients showed highly specific antibody titres (1:12800) in ELISA, eleven had titers $1: 32$ in RID and one of them was negative for both tests. The Nested-PCR reactions could detect the specific fragment of $387 \mathrm{bp}$ in seven biopsy samples, including the patient who had been negative for serology. Conclusion: Culturing has been considered a gold standard diagnostic method. However, the results presented here show that culture was unable to detect $P$. brasiliensis in half of the patients evaluated. On the other hand, histopathology detected the pathogen in all samples. The patient who had demonstrated negative serology was shown to be positive by other diagnostic techniques employed. Three patients whose cultures were negative tested showed to be positive in the Nested-PCR reactions, demonstrating the great sensitivity and specificity of this method. The combination of these techniques must be performed, when possible, in P. brasiliensis detection for efficient diagnosis of PCM. Financial support: Capes and FAPESP 